\title{
Entre la tradición y lo moderno, ¿un aprendizaje de la medicina más completo?
}

\author{
Between tradition and modernity, a more complete apprenticeship in medicine?
}

\author{
Federico Leopoldo Rodríguez Weber, ${ }^{*}$ José Luis Ramírez Arias ${ }^{\ddagger}$
}

Hoy nos encontramos en la llamada era de la globalización, en la que los conocimientos, la ciencia, la tecnología y la historia se mezclan y son accesibles universalmente. El ámbito de la enseñanza en la medicina no es la excepción a esta era, pues los profesores que se encuentran involucrados en los procesos educativos buscan que cada alumno logre el mejor aprendizaje posible y que obtenga, además, la información más adecuada. Estos aspectos, junto con los valores, habilidades y destrezas del alumno, conforman la formación médica integral.

Para Driscoll, el aprendizaje es definido como "un cambio persistente en el desempeño, el cual debe producirse como resultado de la experiencia del alumno y su interacción con el mundo". ${ }^{1}$ Con esta definición, encontramos otros puntos de encuentro que se fundamentan con las teorías modernas de aprendizaje, conocidas como conductismo, cognitivismo y constructivismo. ${ }^{2,3}$ A continuación, mencionamos brevemente algunas definiciones y características de cada una de ellas.

El conductismo expresa que la observación del comportamiento del individuo es más importante que comprender las actividades propias o internas del aprendizaje; el comportamiento se enfoca a estímulos específicos y respuestas durante cada aprendizaje, lo que permitirá expresar el cambio del comportamiento. Otra forma de definir lo anterior, es considerar al conductismo como el estudio de las conductas y los comportamientos, no de los estados mentales.

\footnotetext{
* Profesor de Medicina Interna. Facultad Mexicana de Medicina. Universidad La Salle. Director de Pregrado y Postgrado de la Dirección de Educación e Investigación Corporativa GASS.

* Director Médico del Hospital Ángeles Pedregal.
}

Correspondencia:

Dr. Federico Leopoldo Rodríguez Weber

Correo electrónico: fweber@saludangeles.com

Aceptado: 25-04-2019.

www.medigraphic.com/actamedica

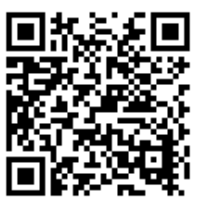

El cognitivismo afirma que el conocimiento es el resultado de las construcciones mentales simbólicas en la percepción del alumno, que requiere de un proceso mediante el cual estas construcciones sean registradas en la memoria; esto es el fundamento del aprendizaje llevado a cabo como un proceso dinámico, participativo e interactivo.

El constructivismo es una corriente pedagógica basada en la teoría del conocimiento constructivista, el cual postula la necesidad de entregar al estudiante las herramientas necesarias (es decir, generar andamiajes) que le permitan construir sus propios procedimientos para resolver una situación problemática, lo que implica que, aunque sus ideas puedan verse modificadas, seguirá aprendiendo. El constructivismo propone un paradigma en el que el proceso de enseñanza se percibe y se lleva al sujeto, de modo que el conocimiento sea una auténtica construcción operada por la persona que aprende. ${ }^{1}$

El conductismo y el cognitivismo en conjunto contemplan el aprendizaje como el acto de aprender el conocimiento. El constructivismo asume que los alumnos no son simples recipientes para ser "llenados" con conocimientos, sino que, como aprendices, seleccionan, persiguen y construyen su propio conocimiento.

El aprendizaje no es ajeno a los cambios mencionados y, hoy, aparece en este campo una nueva teoría conocida como el conectivismo, que en realidad es la combinación o la conexión del cognitivismo y el constructivismo. Es una teoría para la era digital que explica el efecto de la tecnología en el aprendizaje y en la comunicación; lo anterior no estaba contemplado en el cognitivismo ni en el constructivismo. Esta teoría tiene la orientación para comprender que las decisiones están basadas en principios que cambian rápidamente, como sucede en la ciencia y en la tecnología, lo que facilita distinguir nuevas informaciones y tecnologías que puedan alterar el entorno educativo y formen el nodo de una red.

Los grandes cambios, que ya se iniciaron hace algunos años y que actualmente continúan sucediendo, son los escenarios presentes y futuros de tendencia global, y que en la actualidad son imperantes en la educación. Univer- 
salmente, ya se hacen esfuerzos para mejorar la calidad en todos los ámbitos y, por ello, hay grandes trasformaciones e innovaciones en la actividad pedagógica. Esta situación brevemente mencionada no escapa en el ámbito de la educación médica. ${ }^{4}$

En estos tiempos, para ser profesor de medicina no es suficiente con ser un buen profesional de la salud, sino que se debe estar comprometido con el desarrollo de competencias mediante la profesionalización educativa. El docente debe realizar una reflexión de cómo debe ser y cómo debería ser el papel de él mismo en la medicina, así como conocer qué estrategias son las necesarias para aplicarlas en su labor en el aula y en los diferentes escenarios de práctica clínica. El hecho de que un médico trabaje en hospitales con programas docentes universitarios de pregrado y de postgrado y que esté interesado en participar como profesor, no es suficiente para hacerlo docente, y menos un buen docente; un buen profesor debe estar en una organización en donde la universidad se preocupe por vigilar la calidad del proceso, estimule la formación pedagógica, aborde éticamente las situaciones de oportunidad del aprendizaje, establezca una comunicación adecuada con los estudiantes, con el profesor y sus colegas, fomente el trabajo en equipo ${ }^{5}$ (no olvidando el aprendizaje en línea como un recurso indispensable y complementario en nuestro tiempo); todo esto facilitará la educación con los mejores estándares científicos y académicos. Dentro de las competencias específicas de la labor docente que deben desarrollar los profesores en medicina se encuentran, entre otras, las disciplinarias, investigativas, comunicativas, académico-administrativas, psicopedagógicas y humanísticas.

Hace algunos años, estar en un paso de visita o en un aula con los estudiantes, internos y residentes utilizando sus dispositivos móviles hubiera sido tomado como una falta de respeto y de poco interés por parte de los integrantes del grupo; sin embargo, hoy día es común que los médicos en formación recurran a estos dispositivos para acceder al conocimiento reciente $y$, de esta manera, puedan aportar información de los temas que se traten en una forma expedita. No se trata de que hoy se tenga que enseñar a los alumnos al uso de las Tecnologías de Información y Comunicación (TIC), ya que generalmente ellos tienen más conocimiento de su uso, más bien es encaminar y entender el uso de las $\mathrm{TIC}$ al seleccionar las herramientas con perspectivas pedagógicas que mejoren los procesos de enseñanza-aprendizaje e impacten en el progreso académico y de formación en cualquiera de las etapas en las que se encuentre, incluyendo, especialmente, la educación médica continua.
Nunca dejará de ser el paciente el elemento más importante para el aprendizaje del médico ni podrá ser sustituido por algún instrumento o algún otro recurso. Es por ello que el aprendizaje clínico debe estar acompañado de habilidades y actitudes enriquecidas con conocimientos, los cuales facilitarán la interpretación y la toma de decisiones, así ganará la confianza y la tranquilidad de los pacientes y sus familiares; el papel de la tecnología, incluyendo los auxiliares utilizados en la educación como podrían ser los simuladores o pacientes artificiales, siempre serán encaminados a mejorar y hacer más segura la atención de los pacientes en la vida real. ${ }^{6,7}$

Hoy, las TIC toman relevancia al aportar recursos para la educación médica mediante el uso de dispositivos móviles como las tabletas, smartphones y el uso de aplicaciones desarrolladas para este fin, ${ }^{8}$ las cuales no se contraponen a la medicina humanística ni a la cama del paciente.

Concluiríamos diciendo - como lo hemos hecho en algún otro escrito- que existen principios y valores que no pueden ser aprendidos mediante las TIC en los dispositivos, ${ }^{9}$ por lo que el papel del docente es esencial en el proceso de formación de los médicos. En este aspecto, los docentes tendrán que profesionalizarse para poder estar actualizados y para que puedan cumplir con las expectativas universitarias y de las instituciones en relación con su propio perfil de educadores. Es necesario, entonces, que consideren que todas las teorías del aprendizaje deben ser puestas en práctica sin rechazar ninguna de ellas, ya que todas tienen elementos de utilidad para la vida diaria.

\section{REFERENCIAS}

1. Driscoll M. Psychology of learning for instruction. 3a. Ed., USA, Allyn and Bacon, 2000.

2. Saéz LJ. La práctica pedagógica de las tecnologías de la información y la comunicación y su relación con los enfoques constructivistas [Internet]. Disponible en: http://www.rinace.net/reice/numeros/arts/ vol10num1/art4_htm [Accesado en abril de 2019].

3. Siemens G. Conectivismo: una teoría del aprendizaje para la era digital. Disponible en: http://www.scribd.com/doc/201419/ [Accesado en Abril de 2019].

4. Centeno A. Las ciencias del aprendizaje: su potencial influencia en la enseñanza de la medicina. Rev Argent Educ Médica. 2014; 6 (2): 43-44.

5. Hegazi I, Wilson I. Maintaining empathy in medical education. Med Teach. 2013; 35 (12): 1002-1008.

6. Lifshitz GA. La enseñanza de la clínica en la era moderna. Investigación Educ Médica. 2012; 1 (4): 210-217.

7. Ramírez AJ, Rodríguez WF, Ocampo LR. La educación médica para las últimas generaciones. Acta Med. 2018; 16 (3): 267-270.

8. Briz PL, Juanes MJ, García-Peñalvo FJ. Dispositivos móviles y apps: Características y uso actual en educación médica. Revista de la Asociación de Técnicos en Informática. 2015; 231: 86-91.

9. Rodríguez WFL. Principios y valores, nuevas generaciones y la práctica médica. Mes Int Mex. 2018; 34 (3): 477-479. 